\title{
Access to Intrathecal Baclofen Treatment for Children with Cerebral Palsy in European Countries: An SCPE Survey Reveals Important Differences
}

\author{
Kate Himmelmann ${ }^{1,20}$ Magnus Påhlman ${ }^{2}$ Guro L. Andersen ${ }^{3}$ Torstein Vik ${ }^{4}$ Daniel Virella ${ }^{5}$ \\ Karen Horridge ${ }^{6,7}$ David Neubauer $^{8}$ Catherine Arnaud ${ }^{9,10} \quad$ Gija Rackauskaite $^{11}$ Javier de la Cruz ${ }^{12}$
}

${ }^{1}$ Department of Pediatrics, Institute of Clinical Sciences, Sahlgrenska Academy at the University of Gothenburg, Gothenburg, Sweden

2 Regional Rehabilitation Centre, Queen Silvia Children's Hospital, Sahlgrenska University Hospital, Gothenburg, Sweden

${ }^{3}$ The Cerebral Palsy Register of Norway, Vestfold Hospital Trust, Tönsberg, Norway

${ }^{4}$ Department of Laboratory Medicine, Children's and Women's Health, Faculty of Medicine, Norwegian University of Science and Technology, Trondheim, Norway

${ }^{5}$ The Cerebral Palsy Registry of Portugal, Área da Mulher, Criança e Adolescência, Centro Hospitalar Universitário de Lisboa Central, Lisboa, Portugal

6 Paediatric Department, Sunderland Royal Hospital, Sunderland, United Kingdom

7 The North of England Collaborative Cerebral Palsy Survey, Regional Maternity Survey Office, Public Health England, Newcastle upon Tyne, United Kingdom
Address for correspondence Kate Himmelmann, MD, PhD, Regional Rehabilitation Centre, Queen Silvia Children's Hospital, Sahlgrenska University Hospital, Box 210 62, SE 41804 Göteborg, Sweden (e-mail: kate.himmelmann@vgregion.se).

${ }^{8}$ Department of Pediatric Neurology, University Children's Hospital, Ljubljana, Slovenia

9 UMR 1027 Inserm U, Toulouse III University, Toulouse, France

${ }^{10}$ Clinical epidemiology Unit, University Hospital, Toulouse, France

${ }^{11}$ Child and Adolescent Medicine, Aarhus University Hospital, Aarhus, Denmark

${ }^{12}$ Clinical Research Unit, Imas12-Ciberesp, Hospital 12 Octubre, Madrid, Spain

Neuropediatrics 2020;51:129-134.

\begin{abstract}
Keywords

- cerebral palsy

- intrathecal baclofen

- survey

- advanced care

- children

Aim The aim is to study access to intrathecal baclofen (ITB) for children with cerebral palsy (CP) in Europe, as an indicator of access to advanced care.

Methods Surveys were sent to CP registers, clinical networks, and pump manufacturers. Enquiries were made about ITB treatment in children born in 1990 to 2005 by sex, CP type, level of gross motor function classification system (GMFCS) and age at the start of treatment. Access to ITB was related to the country's gross domestic product (GDP) and \% GDP spent on health.

Results In 2011 population-based data from Sweden, Norway, England, Portugal, Slovenia, and Denmark showed that 114 (3.4\%) of 3,398 children with CP were treated with ITB, varying from 0.4 to $4.7 \%$ between centers. The majority of the children were at GMFCS levels IV-V and had bilateral spastic CP. In Sweden, dyskinetic CP was the most commonly treated subtype. Boys were more often treated with ITB than girls $(p=0.014)$. ITB was reported to be available for children with CP in 25 of 43 countries. Access to ITB was associated with a higher GDP and \%GDP spent on health $(p<0.01)$. Updated information from 2019 showed remaining differences between countries in ITB treatment and sex difference in treated children was maintained.

Conclusion There is a significant difference in access to ITB for children with CP across Europe. More boys than girls are treated. Access to ITB for children with CP is associated with GDP and percent of GDP spent on health in the country.
\end{abstract}

received

April 16, 2019

accepted after revision

December 9, 2019

published online

March 2, 2020 (c) 2020 Georg Thieme Verlag KG Stuttgart · New York
DOI https://doi.org/

10.1055/s-0040-1701659. ISSN $0174-304 X$. 


\section{Introduction}

In cerebral palsy (CP), secondary complications due to spasticity and dystonia are common. ${ }^{1}$ Pain has been shown to impact the quality of life of children with $\mathrm{CP}$ in a large multicenter study, the SPARCLE project (Study of Participation of Children with Cerebral Palsy Living in Europe). ${ }^{2}$ The followup routines and access to intervention regarding spasticity in $\mathrm{CP}$ are thought to vary greatly over Europe. One example is the access to intrathecal baclofen treatment (ITB) for severe spasticity and dystonia. ${ }^{3-5}$ The continuous administration of baclofen directly into the intrathecal space requires the implantation of a pump. This treatment reduces the increased muscle tone from spasticity and/or dystonia and can improve sleep, pain management, and quality of life in children with spastic and dyskinetic $\mathrm{CP}$, and has been shown to be costeffective. ${ }^{6,7}$ Long-term effects in reduction of muscle tone have been shown. ${ }^{8,9} \mathrm{~A}$ recent randomized trial reports promising results in achieving treatment goals compared with placebo. ${ }^{10}$ This advanced treatment is concentrated in a limited number of centers in each country, usually in connection with neurosurgery clinics, and therefore easily surveyed. As part of a 3-year program, the SCPE-NET (http://www. scpenetwork.eu) utilized the existing collaboration of 21 population-based registers in 14 European countries-Surveillance of Cerebral Palsy in Europe (SCPE) ${ }^{11}$ to promote best practice and to document variations in access to health care and in health outcomes. As an example of management of children with CP, ITB was chosen as indicator for access to advance care. It was hypothesized that the access to this treatment for children and young people with $\mathrm{CP}$ is unevenly distributed across Europe.

The aim of this study was to survey the current availability and access to ITB treatment for children with $\mathrm{CP}$ in different countries in Europe. Moreover, we wanted to describe the occurrence of ITB treatment in children with $\mathrm{CP}$ by gender, $\mathrm{CP}$ type, gross motor function, and age at the start of treatment. We hypothesized that children with CP living in countries with a high gross domestic product (GDP) were more likely to have access to this treatment than children living in countries with lower GDP.

\section{Methods}

The occurrence of ITB treatment was determined with a register-based study. In 2011, a first survey (-Supplementary Material S1, online only) was sent to SCPE population-based registry partners and clinical networks, exploring the possibilities of data collection regarding children with $\mathrm{CP}$ and ITB. Registers were asked to provide data on children with spastic and dyskinetic $\mathrm{CP}$ according to the $\mathrm{CP}$ classification by SCPE, ${ }^{11}$ at all Gross Motor Function Classification System (GMFCS) levels, ${ }^{12}$ and born in between 1990 and 2005. Information on centers providing ITB in the area was elicited. In a second survey (-Supplementary Material S2, online only), SCPE partners and clinical networks willing to contribute provided aggregated data on presence of ITB treatment by sex, CP type, GMFCS level, and age at implant of a baclofen pump.
The availability and access to ITB on national/regional/ local level were explored with a third questionnaire (-Supplementary Material S3, online only) sent to all CP registers, SCPE partners, known centers, and clinical networks in countries across Europe. Additional information on the availability in European countries was accessed through Medtronic, Tricumed, and Codman, manufacturers of medical pumps. Updated information was requested in 2019.

Availability of ITB treatment was related to economic indicators by country GDP, percentage of GDP spent on health for each of the participating countries (\% GDP), and the Gini coefficient, a measure of inequality of income, varying from 0 (complete equality) to 1.0 (complete inequality). Economic indicators were retrieved from the CIA Factbook. ${ }^{13}$

\section{Statistics}

Group comparisons were made using Chi-square test. The gender distribution in the dataset was compared with the gender distribution in the large SCPE common database. Spearman's correlation was used to study correlations between the presence of ITB treatment and the GDP, \% GDP used for health services and the Gini coefficient.

\section{Results}

Aggregated data from population-based registers were provided by Sweden, Norway, northern England, Portugal (Lisbon area), Slovenia, and Denmark. In total, 114 of 3,398 (3.4\%) children with $\mathrm{CP}$ from the reported areas and birth years were treated with ITB, ranging from $0.4 \%$ in the Lisbon area, Portugal, to $4.7 \%$ in southwestern Sweden. Norway reported the youngest implant age, with 11 of 24 children receiving ITB before 5 years of age ( - Table $\mathbf{1}$ ).

Differences in treatment practices across Europe were found, whereby children with bilateral spastic CP were the most commonly treated group, except in Sweden, where children and young people with dyskinetic CP comprised the largest group. In all, 95\% of the treated children and young people were nonwalkers (GMFCS IV-V).

In addition to the information provided by these population-based registers one center in Belgium and four in the Netherlands provided additional information approximately 80 children in total. These centers reported ITB in occasional walkers, while the majority of children with ITB were nonwalkers, and age at implant in most cases was $>7$ years (range 5-19).

Among all 114 children treated with ITB, 80 (70\%) were boys. This proportion is higher than the proportion of boys (59\%) among 6,849 children and young people born between 1990 and 2004 and registered in the SCPE common database $\left(x^{2}=6.03 ; p=0.0141\right)$. This sex difference persisted when the comparison was restricted to children unable to walk (GMFCS levels IV-V) $\left(x^{2}=4.76 ; p=0.029\right)$. At country/center level, 27 of 32 responders from CP registers and their clinical networks in 22 countries across Europe reported on availability of ITB for children with CP ( - Table 2). Information gathered from the manufacturers of medical pumps active in Europe was 
ITB for CP in Europe Himmelmann et al. 131

Table 1 ITB treatment in children with cerebral palsy in Sweden, Norway, Portugal, Northern England, Slovenia, and Denmark

\begin{tabular}{|c|c|c|c|c|c|c|c|c|c|c|c|c|}
\hline \multirow[t]{2}{*}{$\begin{array}{l}\text { Country } \\
\text { Birth years }\end{array}$} & \multicolumn{2}{|c|}{$\begin{array}{l}\text { Sweden } \\
\text { (west/south) } \\
1990-2005\end{array}$} & \multicolumn{2}{|c|}{$\begin{array}{l}\text { Norway } \\
1999-2005\end{array}$} & \multicolumn{2}{|c|}{$\begin{array}{l}\text { Portugal, } \\
\text { Lisbon area } \\
\text { 1996-1997 } \\
2001-2002\end{array}$} & \multicolumn{2}{|c|}{$\begin{array}{l}\text { Northern } \\
\text { England } \\
\text { 1990-2005 }\end{array}$} & \multicolumn{2}{|c|}{$\begin{array}{l}\text { Slovenia } \\
1990-2005\end{array}$} & \multicolumn{2}{|c|}{$\begin{array}{l}\text { Denmark } \\
\text { 1997-2003 }\end{array}$} \\
\hline & ITB (\%) & $\begin{array}{l}\text { no } \\
\text { ITB }\end{array}$ & ITB (\%) & $\begin{array}{l}\text { no } \\
\text { ITB }\end{array}$ & ITB (\%) & $\begin{array}{l}\text { no } \\
\text { ITB }\end{array}$ & ITB (\%) & $\begin{array}{l}\text { no } \\
\text { ITB }\end{array}$ & ITB (\%) & $\begin{array}{l}\text { no } \\
\text { ITB }\end{array}$ & ITB (\%) & $\begin{array}{l}\text { no } \\
\text { ITB }\end{array}$ \\
\hline \multicolumn{13}{|l|}{ Sex } \\
\hline$M$ & $43(6.3)$ & 637 & $17(4.6)$ & 355 & $1(0.7)$ & 143 & $1(2.9)$ & 34 & $3^{a}$ & & $15(2.9)$ & 521 \\
\hline $\mathrm{F}$ & $13(2.5)$ & 505 & $7(2.7)$ & 256 & $0(0)$ & 86 & $0(0)$ & 16 & $1^{a}$ & & $13(3.4)$ & 368 \\
\hline Total & $56(4.7)$ & 1,142 & $24(3.8)$ & 611 & $1(0.4)$ & 229 & $1(2)$ & 50 & $4(1.1)$ & $363^{a}$ & $28(3)$ & 889 \\
\hline \multicolumn{13}{|l|}{ GMFCS } \\
\hline$|-I|$ & $1(0.001)$ & 702 & $0(0)$ & 409 & $0(0)$ & 80 & $0(0)$ & 27 & 0 & & $2(0.4)$ & 507 \\
\hline III & $1(1)$ & 100 & $1(0.2)$ & 53 & $0(0)$ & 34 & $0(0)$ & 5 & 1 & & $0(0)$ & 34 \\
\hline IV & $10(5.2)$ & 182 & $6(10.5)$ & 51 & $0(0)$ & 38 & $0(0)$ & 5 & 0 & & $3(2)$ & 146 \\
\hline V & 44 (22.9) & 148 & $17(17.2)$ & 82 & $1(1.4)$ & 68 & $1(100)$ & 1 & 3 & & $23(10.5)$ & 197 \\
\hline Unknown & 0 & 10 & $0(0)$ & 16 & 0 & 9 & $0(0)$ & 12 & 0 & & $0(0)$ & 5 \\
\hline Total & $56(4.7)$ & 1,142 & $24(3.8)$ & 611 & $1(0.4)$ & 229 & $1(2)$ & 50 & $4(1.1)$ & $363^{a}$ & $28(3)$ & 889 \\
\hline \multicolumn{13}{|l|}{ CP type } \\
\hline USCP & $0(0)$ & 406 & $0(0)$ & 278 & $0(0)$ & 42 & $0(0)$ & 16 & 0 & & $0(0)$ & 367 \\
\hline $\mathrm{BSCP}$ & $20(3.8)$ & 504 & $20(7.6)$ & 243 & $1(0.7)$ & 154 & $1(3)$ & 32 & 2 & & $19(4.2)$ & 435 \\
\hline Dysk CP & 34 (17.9) & 156 & $4(7.8)$ & 47 & $0(0)$ & 33 & $0(0)$ & 2 & 2 & & 9 (10.7) & 75 \\
\hline Mixed & $2(5.7)$ & 33 & $0(0)$ & 8 & $0(0)$ & 0 & $0(0)$ & 0 & 0 & & $0(0)$ & 0 \\
\hline Unknown & $0(0)$ & 43 & $0(0)$ & 35 & $0(0)$ & 0 & $0(0)$ & 0 & 0 & & $0(0)$ & 12 \\
\hline Total & $56(4.7)$ & 1142 & $24(3.8)$ & 611 & $1(0.4)$ & 229 & $1(2)$ & 50 & $4(1.1)$ & $363^{a}$ & $28(3)$ & 889 \\
\hline \multicolumn{13}{|l|}{$\begin{array}{l}\text { Age at } \\
\text { implant }\end{array}$} \\
\hline$<5 y$ & $4(7.1)$ & & $11(45.8)$ & & $0(0)$ & & $0(0)$ & & $0(0)$ & & & \\
\hline $5-9 y$ & $24(42.8)$ & & $8(33.3)$ & & $0(0)$ & & $0(0)$ & & $1(25)$ & & & \\
\hline $10 \mathrm{y}+$ & $28(50)$ & & $0(0)$ & & $0(0)$ & & $1(100)$ & & $3(75)$ & & & \\
\hline Unknown & $0(0)$ & & $5(20.8)$ & & $1(100)$ & & $0(0)$ & & $0(0)$ & & $28(100)$ & \\
\hline Total & 56 & & 24 & & 1 & & 1 & & 4 & & 28 & \\
\hline
\end{tabular}

Abbreviations: BSCP, bilateral spastic cerebral palsy; CIA, Central Intelligence Agency; CP, cerebral palsy; GMFCS, Gross Motor Function Classification System; ITB, intrathecal baclofen; USCP, unilateral spastic cerebral palsy.

${ }^{a}$ No information of sex distribution, GMFCS distribution, and CP subtypes was received from Slovenia regarding children without ITB. No information on age of implant was received from Denmark.

added to this, indicating access to ITB for children with CP in 25 of 43 countries. Access to ITB for children was correlated to GDP per capita (Spearman's rho $=0.684 ; p<0.01$ ) and to \%GDP spent on health (Spearman's rho $=0.589 ; p<0.01$ ). There was no correlation between access to ITB and the Gini coefficient (Spearman's rho $-0.217, p=0.162$ ).

Updated information received in 2019 from Portugal, Denmark, Northern England, Norway, Slovenia, and Sweden showed that the occurrence of ITB in Norway, Denmark, and Sweden was still higher than in Slovenia and Northern England. An increased occurrence of ITB in Portugal in older children and young adults was seen (-Table 3 ). In the participating area of Northern England there was no ITB treatment to report. In total, there was still a male predominance in ITB treatment. However, the sex distribution was more even in Denmark and Portugal. Incomplete data on age at implant suggested remaining differences, with more than half of the baclofen pumps implanted before 5 years of age in Norway, while all but one was implanted at 10 years of age or later, in Portugal (-Table 3 ).

In 2019, ITB was available in 31 of 43 countries, according to manufacturers.

\section{Discussion}

Based on current literature, ITB treatment in children with CP is not yet a standard practice and not yet considered sufficiently evidence-based to be recommended. ${ }^{14}$ However, there is consensus on the appropriate use of ITB in children with spasticity and dystonia. ${ }^{15,16}$ Evidence on the benefits of ITB is emerging regarding dyskinetic $\mathrm{CP},{ }^{17}$ which has been less studied than spastic $\mathrm{CP},{ }^{16}$ and a randomized-controlled trial has recently 
132 ITB for CP in Europe Himmelmann et al.

Table 2 Availability of intrathecal baclofen treatment (ITB) for children in European countries, based upon information from three manufacturers of medical pumps, used for ITB, and information from 32 responders from 22 countries across Europe, reporting about availability of ITB for children with CP. Gross domestic product (GDP) and percentage of GDP spent on health in the countries where ITB is available for children with cerebral palsy

\begin{tabular}{|c|c|c|c|}
\hline $\begin{array}{l}\text { European countries where intrathecal baclofen was } \\
\text { available for children with cerebral palsy in } 2011\end{array}$ & $\begin{array}{l}\text { Gross domestic product (GDP) } 2011 \\
\text { (International dollar) }\end{array}$ & $\begin{array}{l}\% \text { of GDP spent } \\
\text { on health } 2011\end{array}$ & $\begin{array}{l}\text { Gini coefficient } \\
2011\end{array}$ \\
\hline Austria & 41.7 & 9.9 & 0.26 \\
\hline Belgium & 37.6 & 9.5 & 0.28 \\
\hline Denmark & 40.2 & 9.5 & 0.24 \\
\hline Finland & 38.3 & 7.6 & 0.27 \\
\hline France & 35.0 & 11.1 & 0.33 \\
\hline Georgia & 5.4 & 8.4 & 0.41 \\
\hline Germany & 37.9 & 10.4 & 0.27 \\
\hline Greece & 27.6 & 9.9 & 0.33 \\
\hline Hungary & 19.6 & 7.6 & 0.25 \\
\hline Iceland & 38.0 & 9.3 & 0.28 \\
\hline Ireland & 39.5 & 7.5 & 0.34 \\
\hline Italy & 30.1 & 9.0 & 0.32 \\
\hline Luxembourg & 84.7 & 7.2 & 0.26 \\
\hline Netherlands & 42.3 & 9.3 & 0.31 \\
\hline Norway & 53.0 & 8.7 & 0.25 \\
\hline Poland & 20.1 & 6.2 & 0.34 \\
\hline Portugal & 23.2 & 10 & 0.39 \\
\hline Romania & 12.3 & 5.7 & 0.33 \\
\hline Slovakia & 23.4 & 7.0 & 0.26 \\
\hline Slovenia & 29.1 & 8.4 & 0.28 \\
\hline Spain & 30.6 & 8.1 & 0.32 \\
\hline Sweden & 40.6 & 8.9 & 0.23 \\
\hline Switzerland & 43.4 & 11.3 & 0.34 \\
\hline Turkey & 14.6 & 5.6 & 0.40 \\
\hline United Kingdom & 35.9 & 8.4 & 0.34 \\
\hline \multicolumn{4}{|l|}{ No ITB available for children in 2011} \\
\hline Belarus & 14.9 & 6.4 & 0.27 \\
\hline Bosnia Herzegovina & 8.2 & 8.3 & 0.36 \\
\hline Bulgaria & 13.5 & 6.9 & 0.45 \\
\hline Croatia $^{a}$ & 18.3 & 7.5 & 0.27 \\
\hline Czech Republic $^{\mathrm{a}}$ & 25.9 & 6.8 & 0.31 \\
\hline Estonia $^{a}$ & 20.2 & 5 & 0.31 \\
\hline Kazakhstan & 13 & 3.7 & 0.27 \\
\hline Latvia & 15.4 & 6 & 0.35 \\
\hline Lithuania $^{a}$ & 18.7 & 6.2 & 0.36 \\
\hline Macedonia & 10.4 & 8.2 & 0.44 \\
\hline Malta & 25.7 & 8.3 & 0.26 \\
\hline Moldova & 3.4 & 7.8 & 0.38 \\
\hline Montenegro & 11.2 & 6.8 & 0.24 \\
\hline Russia $^{a}$ & 16.7 & 5.3 & 0.42 \\
\hline Serbia $^{a}$ & 10.7 & 7.6 & 0.28 \\
\hline Ukraine & 7.2 & 7 & 0.28 \\
\hline
\end{tabular}

andicates additional countries with confirmed ITB for children in the 2019 update. 
Table 3 Sex differences and age at implant in reported intrathecal baclofen treatment of children with cerebral palsy from Denmark, Portugal, Norway, and Sweden 2019. No information about sex or age at implant was received from Slovenia

\begin{tabular}{|l|l|l|l|l|l|l|}
\hline $\begin{array}{l}\text { Country } \\
\text { Birth years }\end{array}$ & & \multicolumn{3}{|l|}{ Age at implant (years) } \\
\cline { 2 - 7 } & M (\%) & F (\%) & $<5$ & $\mathbf{5 - 9}$ & $\mathbf{1 0}+$ & Unknown \\
\hline Denmark (2004-2007) & 12 & 10 & & & $22^{\text {a }}$ \\
\hline Norway (1999-2013) & 37 & 14 & 29 & 17 & 0 & 5 \\
\hline Portugal (Lisbon area) (1990-2005) & 5 & 6 & 0 & 1 & 10 & 0 \\
\hline Sweden (west and south) (2000-2015) & 24 & 11 & 3 & 16 & 16 & 0 \\
\hline Total & $78(66)$ & $41(34)$ & 32 & 34 & 26 & 27 \\
\hline
\end{tabular}

aNo information on age of implant was received from Denmark.

been published, showing that ITB is superior to placebo in achieving treatment goals in severe dyskinetic $\mathrm{CP} .{ }^{10}$ The longterm safety and efficacy have been described, and cost-effectiveness of this treatment has been shown. ${ }^{8,9}$ ITB is frequently used in some countries, mostly in nonwalkers, to increase comfort, by reducing spasticity, dystonia, and pain. Some centers also use ITB for children and young people who are able to walk, with or without devices, to gain or improve function, mostly pertaining to mobility and walking.

The present study reveals that children with $\mathrm{CP}$ in many European countries have access to treatment with ITB. The use of ITB was associated with \% of GDP spent on health in the country, which is not surprising. To utilize this possibility, physicians need to include it in treatment programs for CP. An obstacle may be that it is considered an expensive treatment, thus the message of cost-effectiveness must be emphasized.

However, our results at patient level suggest that having access to ITB may not mean that the access to ITB is easy. This is highlighted by the variation of ITB treatment ranging from 0.4 to $4.7 \%$ in 2011 . Updated information from 2019 suggests that there is still some variation between countries. Different treatment traditions, or awaiting further evidence of the treatment effects may also be possible reasons for not using ITB, despite increasing availability.

Boys constituted $70 \%$ of the total group of children treated with ITB in this study. The difference in treatment with ITB between boys and girls does not mirror the actual sex difference in $\mathrm{CP}$, although there is a male predominance in $\mathrm{CP}{ }^{18}$ Some authors have described sex differences in children with $\mathrm{CP}$ affecting the surgeon's choice of orthopedic treatment and in outcome after interventions. ${ }^{19,20}$ Other studies report that boys with $\mathrm{CP}$ more often are treated with botulinum toxin ${ }^{21}$ and more often have physiotherapy. ${ }^{22}$ One potential explanation for this sex difference may be that although GMFCS levels are the same, spasticity and dystonia are less pronounced in girls although we are not aware of any publications supporting this speculation. Conversely, in a recent study from the SPARCLE project, girls reported more pain than boys, ${ }^{23}$ and a more likely hypothesis is that girls in fact have less access to treatment than boys, despite comparable needs. ${ }^{24}$

Although the SCPE network has members in many European countries, these are mainly registers, which may not have close clinical networks. This probably limited the recruitment of participants in this study. Therefore, the study does not cover all European countries, and the areas within countries that have reported may not be representative for the whole country. One example is Northern England, where only one baclofen pump had been inserted during the study period. This may not be representative of United Kingdom, as in other areas, ITB is more frequently used. However, we had no population-based data from these areas. On country/ center level we have tried to access all centers and manufacturers. However, there may be centers or manufacturers that we have not reached, or who have not replied. Additionally, the age range of children at data collection was wide, between 5 and 18 years. Thus, the proportion of treated children in the countries reporting from the lowest ages may be underestimated.

Larger studies on ITB treatment in children with CP may lead to further development of treatment standards and recommendations, based on sound evidence, ${ }^{14}$ and serve as a basis for informed decisions about ITB, and as an argument for ITB in countries and regions that do not yet offer this treatment to children with CP. Such studies may also reduce perceived delay in treatment, discussed recently by Berman et al. ${ }^{25}$

We conclude that there are significant differences in access to ITB treatment for children with CP across Europe, which illustrate the inequalities in health care that these children face. Furthermore, the frequency of ITB treatment differs between boys and girls.

Conflict of Interest

None.

\section{Acknowledgments}

This study was performed on behalf of the SCPE collaboration and was funded by the European Union Health Program-Grant Number DG SANCO EAHC 20081307 - "Surveillance of Cerebral Palsy in Europe: best practice in monitoring, understanding of inequality, and dissemination of knowledge."

We are grateful to all centers across Europe contributing data to this study.

Medtronic, Tricumed, and Codman manufacturers of medical pumps used for intrathecal baclofen treatment, provided information regarding availability of treatment in European countries. 


\section{References}

1 Hägglund G, Andersson S, Düppe H, Lauge-Pedersen H, Nordmark E, Westbom L. Prevention of severe contractures might replace multilevel surgery in cerebral palsy: results of a population-based health care programme and new techniques to reduce spasticity. J Pediatr Orthop B 2005;14(04):269-273

2 Dickinson HO, Parkinson KN, Ravens-Sieberer U, et al. Self-reported quality of life of 8-12-year-old children with cerebral palsy: a crosssectional European study. Lancet 2007;369(9580):2171-2178

3 Albright AL, Cervi A, Singletary J. Intrathecal baclofen for spasticity in cerebral palsy. JAMA 1991;265(11):1418-1422

4 Albright AL, Barry MJ, Painter MJ, Shultz B. Infusion of intrathecal baclofen for generalized dystonia in cerebral palsy. J Neurosurg 1998;88(01):73-76

5 Motta F, Stignani C, Antonello CE. Effect of intrathecal baclofen on dystonia in children with cerebral palsy and the use of functional scales. J Pediatr Orthop 2008;28(02):213-217

6 de Lissovoy G, Matza LS, Green H, Werner M, Edgar T. Costeffectiveness of intrathecal baclofen therapy for the treatment of severe spasticity associated with cerebral palsy. J Child Neurol 2007;22(01):49-59

7 Saulino M, Guillemette S, Leier J, Hinnenthal J. Medical cost impact of intrathecal baclofen therapy for severe spasticity. Neuromodulation 2015;18(02):141-149, discussion 149

8 Campbell WM, Ferrel A, McLaughlin JF, et al. Long-term safety and efficacy of continuous intrathecal baclofen. Dev Med Child Neurol 2002;44(10):660-665

9 Vles GF, Soudant DL, Hoving MA, et al. Long-term follow-up on continuous intrathecal Baclofen therapy in non-ambulant children with intractable spastic cerebral palsy. Eur J Paediatr Neurol 2013;17(06):639-644

10 Bonouvrié LA, Becher JG, Vles JSH, Vermeulen RJ, Buizer AI; IDYS Study Group. The effect of intrathecal baclofen in dyskinetic cerebral palsy: the IDYS trial. Ann Neurol 2019;86(01):79-90

11 Surveillance of Cerebral Palsy in Europe. Surveillance of cerebral palsy in Europe: a collaboration of cerebral palsy surveys and registers. Dev Med Child Neurol 2000;42(12):816-824

12 Palisano R, Rosenbaum P, Walter S, Russell D, Wood E, Galuppi B. Development and reliability of a system to classify gross motor function in children with cerebral palsy. Dev Med Child Neurol 1997;39(04):214-223

13 CIA. The World Factbook. 2008. Available at: https://www.cia.gov/ library/publications/the-world-factbook/rankorder/2004rank. html. Accessed April 22, 2012
14 Novak I, McIntyre S, Morgan C, et al. A systematic review of interventions for children with cerebral palsy: state of the evidence. Dev Med Child Neurol 2013;55(10):885-910

15 Dan B, Motta F, Vles JS, et al. Consensus on the appropriate use of intrathecal baclofen (ITB) therapy in paediatric spasticity. Eur J Paediatr Neurol 2010;14(01):19-28

16 Berweck S, Lütjen S, Voss W, et al; ITB Working Party. Use of intrathecal baclofen in children and adolescents: interdisciplinary consensus table 2013. Neuropediatrics 2014;45(05): 294-308

17 Eek MN, Olsson K, Lindh K, et al. Intrathecal baclofen in dyskinetic cerebral palsy: effects on function and activity. Dev Med Child Neurol 2018;60(01):94-99

18 Sellier E, Surman G, Himmelmann K, et al. Trends in prevalence of cerebral palsy in children born with a birthweight of $2,500 \mathrm{~g}$ or over in Europe from 1980 to 1998. Eur J Epidemiol 2010;25(09): 635-642

19 Gough M, Shafafy R, Shortland AP. Does sex influence outcome in ambulant children with bilateral spastic cerebral palsy? Dev Med Child Neurol 2008;50(09):702-705

20 Zwick EB, Svehlík M, Kraus T, Steinwender G, Linhart WE. Does gender influence the long-term outcome of single-event multilevel surgery in spastic cerebral palsy? J Pediatr Orthop B 2012;21 (05):448-451

21 Franzén M, Hägglund G, Alriksson-Schmidt A. Treatment with Botulinum toxin A in a total population of children with cerebral palsy-a retrospective cohort registry study. BMC Musculoskelet Disord 2017;18(01):520

22 Degerstedt F, Wiklund M, Enberg B. Physiotherapeutic interventions and physical activity for children in Northern Sweden with cerebral palsy: a register study from equity and gender perspectives. Glob Health Action 2016;10(Suppl 2):1272236

23 Parkinson KN, Dickinson HO, Arnaud C, Lyons A, Colver A; SPARCLE group. Pain in young people aged 13 to 17 years with cerebral palsy: cross-sectional, multicentre European study. Arch Dis Child 2013;98(06):434-440

24 Romeo DM, Sini F, Brogna C, Albamonte E, Ricci D, Mercuri E. Sex differences in cerebral palsy on neuromotor outcome: a critical review. Dev Med Child Neurol 2016;58(08):809-813

25 Berman CM, Eppinger MA, Mazzola CA. Understanding the reasons for delayed referral for intrathecal baclofen therapy in pediatric patients with severe spasticity. Childs Nerv Syst 2015; 31(03):405-413 